\title{
ARTIGO
}

\section{Análise de riscos do uso de um sistema de proteção contra quedas com linha de vida horizontal como proteção de periferia na Construção Civil brasileira}

Risk analysis of a horizontal lifeline active fall protection system used as edge protection in Brazilian Civil Construction

Análisis de riesgos del uso de un sistema de protección contra caimientos con línea de vida horizontal como protección de periferia en la construcción civil brasileña

\section{Miguel C. Branchtein'}

RESUMO: Na construção civil brasileira, há mais de uma década, tem-se disseminado a proteção contra quedas da periferia da obra por meio de um Sistema de Proteção Ativa contra Quedas (SPAQ), ancorado em uma linha de vida horizontal flexível, em detrimento de um Sistema de Proteção Passiva contra Quedas (SPPQ). No entanto, de uma maneira geral, tal uso não tem sido precedido de uma análise de risco que reconheça os riscos existentes e demonstre a segurança e adequação desse sistema. O presente artigo se propõe a proceder a essa análise.

\footnotetext{
${ }^{1}$ Auditor-Fiscal do Trabalho (aposentado); Engenheiro civil; Especialista em Engenharia de Segurança. Laborare. Ano I, Número 1, Julho/2018, pp. 151-179. ISSN 0000-0000. http://trabalhodigno.org/laborare
} 
Análise de riscos do uso de um sistema de proteção contra quedas com linha de vida horizontal como proteção de periferia na Construção Civil brasileira

$\mathrm{Na}$ análise de riscos, verificou-se que no uso de um SPAQ ancorado em linha de vida horizontal flexível para proteção de periferia, há vários riscos de consequências potencialmente graves ou fatais. Recomenda-se considerar a utilização de medidas de controle mais acima na hierarquia, como eliminação do trabalho em altura ou uso de sistemas de proteção passiva. Na impossibilidade disso, proceder a uma análise de risco detalhada, considerando as condições específicas da tarefa, buscando soluções para todos os pontos analisados.

Palavras-Chave: proteção ativa contra quedas; linha de vida horizontal flexível; análise de riscos; segurança e saúde do trabalho; construção civil.

ABSTRACT: In Brazilian construction industry, for more than a decade, edge fall protection have increasingly been done by means of active fall protection systems anchored in flexible horizontal lifelines instead of passive fall protection systems. However, in general, such usage has not been preceded by risk analysis recognizing existing risks and demonstrating the safety and suitability of such a system. This paper aims at carrying out such analysis.

In that risk analysis, it was verified that there are several potentially serious or fatal risks in the use of active edge protection systems anchored in flexible horizontal lifelines. It is recommended to consider the use of control measures higher up in the control hierarchy, such as elimination of work at height or passive protection systems use. If this is not possible, it is recommended to carry out a detailed risk analysis, considering the task specific conditions, and seeking solutions for all the analyzed points.

Keywords: edge fall protection; flexible horizontal lifeline; risk analysis; occupational health and safety; civil construction. 


\section{INTRODUÇÃO}

Anualmente, mais de 374 milhões de acidentes de trabalho ocorrem no mundo e mais de 2,78 milhões de pessoas morrem por causa do trabalho, de acordo com dados da Organização Internacional do Trabalho (OIT, 2018). As perdas econômicas decorrentes são estimadas em 4\% do PIB mundial. Os acidentes e suas consequências podem e devem ser evitados através de medidas adequadas de controle. No Brasil, os dados disponíveis sobre acidentes revelam uma realidade semelhante. Dentre os acidentes fatais, as quedas de altura representam uma alta proporção em relação ao total de casos. Como exemplo, estudos obtidos (BRASIL,2008; BRANCHTEIN; SOUZA, 2009) das análises de acidentes ocorridos no estado do Rio Grande do Sul revelam que as quedas de altura representam mais de $30 \%$ do total de acidentes fatais. $\mathrm{Na}$ indústria da construção, a proporção das fatalidades por quedas é maior, constituindo mais de $50 \%$ do total de acidentes fatais nesta atividade. Além disso, o estudo mostrou que a ausência de um projeto adequado é um dos fatores causais relacionados com acidentes envolvendo queda.

Na construção civil brasileira, há mais de uma década, tem-se disseminado a proteção contra quedas da periferia da obra por meio de um Sistema de Proteção Ativa contra Quedas (SPAQ), ancorado em uma linha de vida horizontal flexível, em detrimento de um Sistema de Proteção Passiva contra Quedas (SPPQ). No entanto, de uma maneira geral, tal uso não tem sido precedido de uma análise de risco que reconheça os riscos existentes e demonstre a segurança e adequação desse sistema. O presente artigo se propõe a proceder a essa análise.

Laborare. Ano I, Número 1, Julho/2018, pp. 151-179. ISSN 0000-0000. http://trabalhodigno.org/laborare 
Análise de riscos do uso de um sistema de proteção contra quedas com linha de vida horizontal como proteção de periferia na Construção Civil brasileira

\section{METODOLOGIA}

$\mathrm{O}$ ponto de partida deste artigo foram as observações efetuadas pelo autor em sua atividade de auditoria fiscal do trabalho. A despeito de não ter havido um registro sistemático das observações, nem sequer seu número, essas abrangeram o período de mais de uma década em que o uso do SPAQ ancorado em uma linha de vida horizontal flexível como proteção de periferia se popularizou. Foram feitas observações das implantações do sistema em vários tipos de obras, e examinada a documentação correspondente, quando existente, como análises de risco, procedimentos operacionais, projetos e memórias de cálculo. Também foram assistidos a alguns ensaios de queda desse tipo de sistema, em obra, com ou sem medições, e em instalações específicas para ensaios de linhas de vida. Ao longo dessas observações, foram identificados riscos relacionados com esse tipo de uso do SPAQ.

Os conceitos fundamentais e os requisitos técnicos e legais referentes ao planejamento do trabalho em altura, ao controle dos riscos e aos sistemas de proteção contra quedas foram expostos nas seções 3 a 6 , fundamentados nas normas nacionais e internacionais e na literatura técnica.

A seguir, foi realizada a análise de riscos do sistema estudado, sendo que as seções 7 e 8 trazem respectivamente: a descrição do sistema, considerando as características comuns às obras onde o sistema pode ser aplicado e as possíveis variações que podem ocorrer; e a identificação dos riscos, suas causas e consequências, realizada através do método FMEA (análise dos modos de falha e efeitos) (ABNT, 2018; ABNT, 2012). 


\section{PLANEJAMENTO DO TRABALHO EM ALTURA}

A melhor forma de promoção da segurança e saúde do trabalho é pelo estabelecimento de um sistema de gestão da segurança e saúde eficiente. Isso tem sido reconhecido nas Diretrizes sobre Sistemas de Gestão de Segurança e Saúde no Trabalho, ILO-OSH 2001, (ILO, 2001) da Organização Internacional do Trabalho (OIT), na OHSAS 18000 - Sistemas de Gestão de Segurança e Saúde Ocupacional (BSI, 2007), e na recentemente publicada ISO 45001 - Sistemas de Gestão de Segurança e Saúde Ocupacional (ISO, 2018).

Nos projetos de construção, a gestão de risco se aplica em todas as fases do ciclo de vida do projeto: concepção e planejamento, execução da obra, utilização, manutenção e demolição. A Convenção 167 da OIT (ILO, 1988) exige que os responsáveis pela concepção e planejamento de um projeto de construção levem em conta a segurança e a saúde dos trabalhadores. No âmbito nacional (BRANCHTEIN, 2016), a Constituição Federal (BRASIL, 1988), no seu artigo $7^{\circ}$, inc. 22, prevê como direito do trabalhador a redução de riscos através de normas de segurança e saúde, e os artigos 155 e 200 da Consolidação das Leis do Trabalho (CLT) (BRASIL, 1943) preveem que suas disposições sobre segurança e saúde do trabalhador sejam regulamentadas por normas do Ministério do Trabalho. Nesse sentido foram publicadas, desde 1978, trinta e seis normas regulamentadoras (NR). Desde 1994, as normas regulamentadoras são elaboradas e revisadas em um processo de consulta tripartite, por representantes dos trabalhadores, empregadores e governo, conforme prescrições da OIT, e submetidas à consulta pública. As normas mais relevantes para o tópico tratado neste artigo são a NR 18 - Condições e Meio Ambiente de Trabalho na Indústria da Construção (BRASIL, 2015b), a NR 35 -Trabalho em Altura (BRASIL, 2016) e a NR 6 - Equipamentos de Proteção Individual - EPI (BRASIL, 2015a). A NR 18 estabelece a necessidade de planejamento através do Programa de Laborare. Ano I, Número 1, Julho/2018, pp. 151-179. ISSN 0000-0000. http://trabalhodigno.org/laborare 
Análise de riscos do uso de um sistema de proteção contra quedas com linha de vida horizontal como proteção de periferia na Construção Civil brasileira

Condições e Meio Ambiente de Trabalho na Indústria da Construção (PCMAT). Já a NR 35 - Trabalho em Altura - tem o planejamento como um de seus pilares, principalmente através da análise de risco e do procedimento operacional, cujo conteúdo mínimo é regulado, respectivamente, nos itens 35.4.5.1 e 35.4.6.1 da norma, acrescido, tratando-se de sistema de proteção contra quedas, dos itens 35.5 .2 da norma e item 5 do anexo II da mesma.

\section{HIERARQUIA DOS SISTEMAS DE CONTROLE DE RISCO}

A NR 35 traz, no planejamento do trabalho em altura, a hierarquia das medidas de controle em que se deve evitar o trabalho em altura, realizando o trabalho no solo, ou em construção sólida e protegida contra quedas, sempre que isso for possível. Quando não, adotar um sistema de proteção contra quedas, preferencialmente que elimine o risco de queda ou, em último caso, que minimize as consequências da queda (BRASIL, 2016; BRASIL, 2018).

\section{CLASSIFICAÇÃO DOS SISTEMAS DE PROTEÇÃO CONTRA QUEDAS}

Conforme ilustrado na Figura 1, há duas classificações de sistemas de proteção contra quedas (Brasil, 2018).

Laborare. Ano I, Número 1, Julho/2018, pp. 151-179. ISSN 0000-0000. http://trabalhodigno.org/laborare 
coletiva, passiva
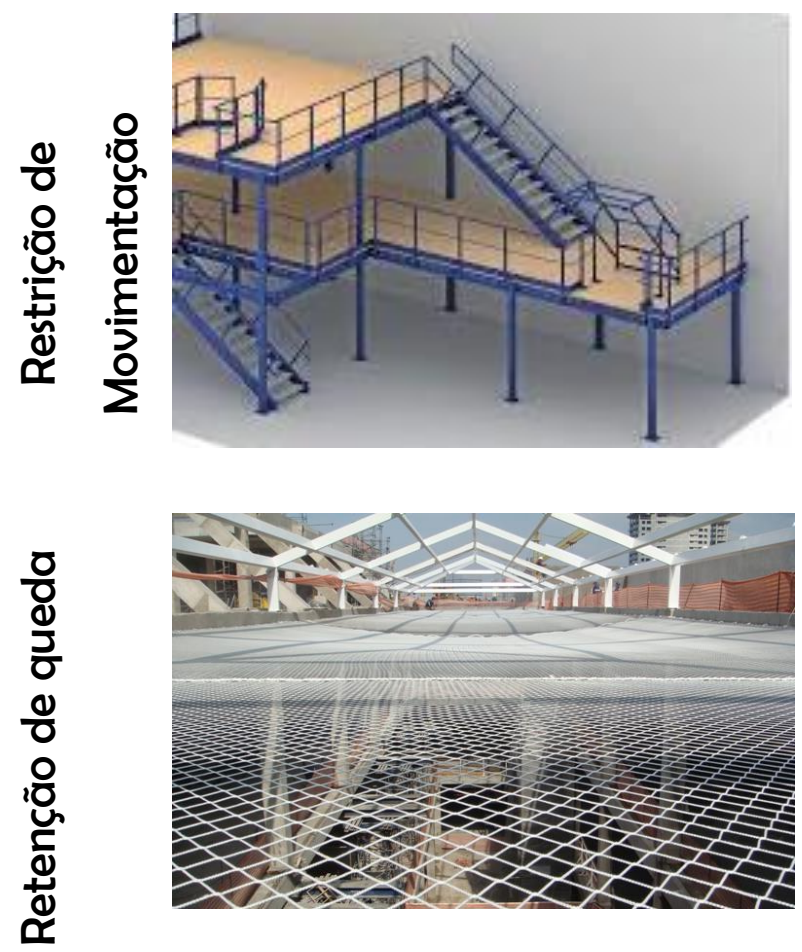

pessoal,ativa
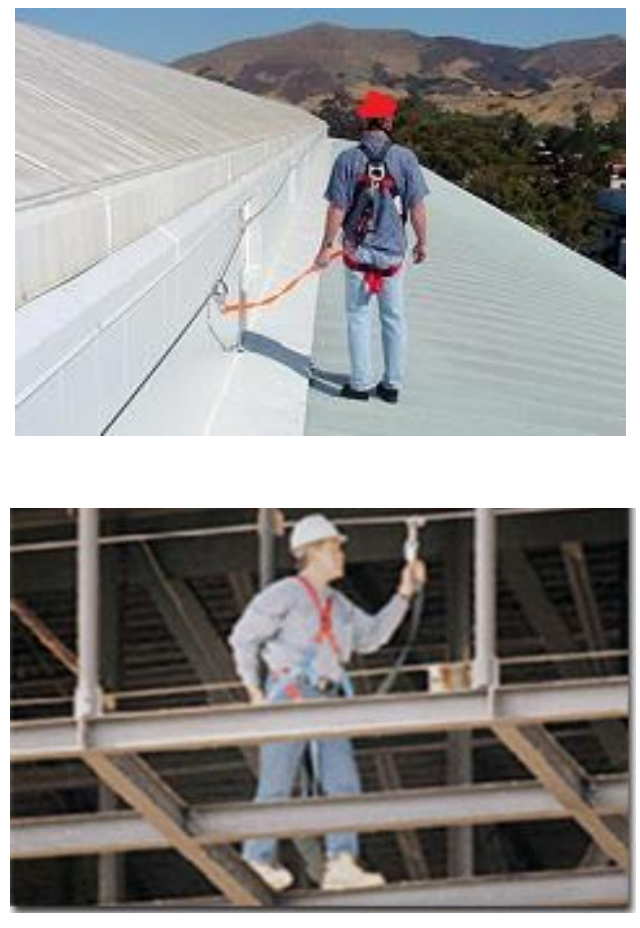

Figura 1. Classificações dos sistemas de proteção contra quedas. (BRASIL, 2018)

\section{Proteção passiva e ativa}

A primeira classificação se refere ao sistema de proteção contra quedas depender ou não da ação do trabalhador que os utiliza. No primeiro caso, são classificados como de sistema de proteção ativa contra quedas (SPAQ) e, no segundo, como sistema de proteção passiva contra quedas (SPPQ). Em geral, o SPPQ corresponde a um equipamento de proteção coletiva e o SPAQ corresponde a um equipamento de proteção individual (EPI). Como exemplos de proteção ativa, existem aqueles que fazem uso de cintos de segurança, talabartes e linhas de vida. E, como exemplo de proteção passiva, as redes de segurança e sistemas de guarda-corpo e rodapé. Os sistemas de proteção ativa requerem treinamentos específicos do trabalhador, Laborare. Ano I, Número 1, Julho/2018, pp. 151-179. ISSN 0000-0000. http://trabalhodigno.org/laborare 
Análise de riscos do uso de um sistema de proteção contra quedas com linha de vida horizontal como proteção de periferia na Construção Civil brasileira

frequentemente determinados em norma regulamentadora, para assegurar que sejam executadas corretamente as ações necessárias para o funcionamento do sistema.

Os sistemas de proteção passiva são preferíveis aos de proteção ativa justamente porque a qualidade da proteção é praticamente independente dos fatores que incidem no elemento humano enquanto em seu ambiente de trabalho.

A precedência da proteção passiva ou coletiva sobre a ativa ou individual está prevista na CLT, art. 166, e em várias normas regulamentadoras, como NR 6, item 6.3; NR 18, item 18.13.1; e NR 35, item 35.5.3.

\section{Restrição de movimentação e retenção de quedas}

Os sistemas de proteção, passiva ou ativa, contra quedas podem subsequentemente ser divididos em duas categorias:

\section{a. Restrição de movimentação.}

O sistema de restrição de movimentação visa impedir que o trabalhador atinja a zona com risco de queda, não permitindo que ela ocorra. Exemplos de tais sistemas são os guarda-corpos. As linhas de vida horizontais também podem ser de restrição de movimentação se realmente impedirem a queda.

\section{b. Retenção de queda.}

O sistema de retenção de queda (também chamado de captura de queda) não impede a queda, e sim as suas consequências. Caracteriza-se por buscar controlar as energias, forças e deslocamentos gerados pela queda de modo a preservar a integridade física do trabalhador. Exemplos de tais sistemas incluem as redes de segurança e também as linhas de vida horizontais.

Laborare. Ano I, Número 1, Julho/2018, pp. 151-179. ISSN 0000-0000. http://trabalhodigno.org/laborare 
É interessante observar que as linhas de vida horizontais podem ser projetadas tanto para restrição de movimentação como para retenção de queda. Não é raro encontrar sistemas projetados para operar como de restrição de movimentação que funcionam, na verdade, como retenção de queda, quando mal projetados, instalados, ou utilizados. Tais sistemas acarretam situações de grande risco, pois os sistemas de restrição de movimentação não são projetados para resistir às forças de intensidade maior que surgem nos sistemas de retenção de queda. É possível, no entanto, projetar sistemas que busquem primariamente prevenir a queda, mas que estejam preparados para reter a queda, caso ocorra.

\section{Análise de Barreiras}

Classificações alternativas dos sistemas de proteção contra quedas são formuladas no contexto do método de análise de barreiras, que, ao invés de focar nas causas dos acidentes, busca entender a sua gênese e prevenção através da análise das barreiras e suas possíveis falhas (Hollnagel; 2004).

Uma barreira pode servir para impedir que um evento ocorra, ou para bloquear ou atenuar o impacto de suas consequências, se ele vier a ocorrer. No primeiro caso, as barreiras dizem-se preventivas; no segundo, protetivas. Um exemplo do primeiro tipo são os sistemas de restrição de movimentação e, do segundo, os de retenção de queda.

Além disso, as barreiras se classificam, quanto à sua natureza, em físicas, funcionais, simbólicas e incorpóreas. As barreiras físicas (também chamadas de barreiras materiais) impedem fisicamente uma ação de ser executada ou um evento de ocorrer, ou também podem bloquear ou mitigar os efeitos de um evento inesperado. Um exemplo é um guarda-corpo. As barreiras funcionais (ativas ou dinâmicas) funcionam impedindo a ação de ser executada por meio de um intertravamento. Um exemplo é a porta de um elevador, que bloqueia o acesso à caixa de corrida quando o elevador não se encontra parado no 
Análise de riscos do uso de um sistema de proteção contra quedas com linha de vida horizontal como proteção de periferia na Construção Civil brasileira

pavimento. Barreiras simbólicas requerem um ato de interpretação de um agente inteligente. Por exemplo, um cartaz indicando que o EPI deve ser utilizado. A última classe são as barreiras incorpóreas (ou imateriais), que não têm forma ou substância material, mas dependem do conhecimento do usuário para atingir seu objetivo. Podem existir ou serem representadas sob forma física, como um livro ou uma ordem de serviço, mas geralmente não estão fisicamente presentes quando seu uso é necessário. Exemplos são os regulamentos, procedimentos de trabalho, conhecimentos e experiência. Existem também sistemas de barreiras compostos. Um SPAQ é um sistema composto por barreiras físicas (cinturão de segurança, elemento de ligação e ancoragem), mas só atende seu propósito se efetivamente usado, para o que depende de barreiras incorpóreas (capacitação, ordens de serviço, experiência), podendo ser reforçadas por barreiras simbólicas, como cartazes. O sucesso do sistema depende da eficácia de cada um desses subsistemas. A qualidade das barreiras pode ser avaliada conforme sua eficiência (ou adequação), recursos requeridos, robustez (confiabilidade), demora na implementação, aplicabilidade a tarefas de segurança críticas, disponibilidade, avaliação e dependência de humanos. A avaliação dos diferentes tipos de barreiras pode ser sintetizada na Tabela 1.

Tabela 1. Avaliação da qualidade do sistema de barreiras

\begin{tabular}{|l|l|l|l|l|}
\hline & \multicolumn{1}{|c|}{ Física } & \multicolumn{1}{|c|}{ Funcional } & \multicolumn{1}{c|}{ Simbólica } & Incorpórea \\
\hline Eficiência & Alta & Alta & Média & Baixa \\
\hline Recursos necessários & Média - Alta & Baixa - Média & Baixa - Média & Baixa \\
\hline Robustez (confiabilidade) & Média - Alta & Média - Alta & Baixa - Média & Baixa \\
\hline Demora na implementação & Grande & Média - Grande & Média & Pequena \\
\hline $\begin{array}{l}\text { Aplicabilidade a tarefas de } \\
\text { segurança críticas }\end{array}$ & Baixa & Média & $\begin{array}{l}\text { Baixa (interpretação } \\
\text { incerta) }\end{array}$ & Baixa \\
\hline Disponibilidade & Alta & Baixa - Alta & Alta & Incerta \\
\hline Avaliação & Fácil & Difícil & Difícil & Difícil \\
\hline Dependência de humanos & Nenhuma & Baixa & Alta & Alta \\
\hline
\end{tabular}

Fonte: HOLLNAGELL, 2004, tab. 3.5 
Por depender de barreiras incorpóreas, os SPAQ apresentam, como vantagem, baixos recursos necessários e pequeno tempo de implementação, mas, como desvantagem, baixa eficiência e confiabilidade, disponibilidade incerta e alta dependência de humanos. Daí a prioridade aos SPPQ, que, sendo barreiras físicas, apesar de maior necessidade de recursos e implantação mais demorada, praticamente não dependem de humanos, são de fácil avaliação, pronta disponibilidade, alta eficiência e confiabilidade.

\section{COMPONENTES DO SISTEMA DE PROTEÇÃO ATIVA CONTRA QUEDAS (SPAQ)}

O sistema de proteção ativa contra quedas pode ser dividido em dois subsistemas: equipamento de proteção individual e sistema de ancoragem (BRASIL, 2018).

\section{Equipamento de Proteção Individual (EPI)}

Composto pelo cinturão de segurança, pelo(s) componente(s) de união e pelo absorvedor de energia individual.

\section{Sistema de ancoragem}

O sistema de ancoragem é um subsistema fundamental de um SPAQ. De nada adianta o EPI contra quedas se não estiver conectado a uma ancoragem, ou se essa ancoragem não resistir aos esforços a que estiver sujeita.

O sistema de ancoragem de um SPAQ é regulamentado pelo anexo II da NR 35.

O sistema de ancoragem pode assumir diversas configurações, das mais simples às mais complexas. O sistema de ancoragem é composto por estrutura, ancoragem estrutural, dispositivo de ancoragem e elementos de fixação. A estrutura sempre faz 
Análise de riscos do uso de um sistema de proteção contra quedas com linha de vida horizontal como proteção de periferia na Construção Civil brasileira

parte de um sistema de ancoragem. Os demais componentes podem ou não estar presentes, dependendo da configuração.

A NBR 16325 (ABNT, 2014) define quatro tipos de dispositivo de ancoragem. Os tipos A e B são pontuais, e os tipos C e D são lineares horizontais, apropriados para tarefas que requerem movimentação ao longo de uma linha com essa direção.

\section{Linha de vida horizontal flexível}

O dispositivo de ancoragem do tipo $\mathrm{C}$ é a linha de vida horizontal flexível (BRANCHTEIN; SOUZA; SIMON, 2015). Consiste em uma linha aproximadamente horizontal, de cabo de aço ou corda ou fita de fibras sintéticas, à qual o componente de união do EPI se conecta, permitindo o deslocamento do trabalhador sem se desconectar do sistema de ancoragem. O cabo é suspenso por pelo menos dois pontos nas extremidades (chamados ancoragem de extremidade), mas pode ter também suportes intermediários (ancoragens intermediárias). Pode ser composta por vários elementos: a linha, ancoragens de extremidade e intermediárias, ponto móvel de ancoragem, absorvedor de energia de linha, tensionador, indicador de tensão. Pode ser em um único vão ou em vários vãos. Pode ser retilínea ou formar ângulos entre dois vãos, ou mesmo formar um circuito fechado. Pode ter um ou mais usuários, sendo que neste caso deve-se considerar a possibilidade de ocorrência de quedas múltiplas, simultâneas ou sequenciais. Pode ter ou não absorvedores de energia de linha, em uma extremidade ou nas duas.

Laborare. Ano I, Número 1, Julho/2018, pp. 151-179. ISSN 0000-0000. http://trabalhodigno.org/laborare 


\section{ANÁLISE DE RISCO: DESCRIÇÃO DO SISTEMA ANALISADO}

Tendo em vista que o sistema ora analisado é utilizado em uma variedade de obras, a descrição do sistema deve considerar as características comuns a todas e as possíveis variações que podem ocorrer.

O sistema estudado é um SPAQ com linha de vida horizontal flexível utilizado como proteção de periferia, excluídos outros tipos de uso. De uma maneira geral, é uma linha de vida horizontal flexível disposta próxima e aproximadamente paralela à periferia de um pavimento ou superfície da obra.

Por vezes é concebido com a finalidade de restrição de movimentação e, em outras, com a de retenção de queda.

A superfície pode ser um plano horizontal, como uma laje de concreto ou a forma para concretar essa laje, uma plataforma de proteção contra queda de materiais (bandeja), ou um andaime em balanço. Ou pode ser um plano inclinado, como um telhado.

Geralmente, a linha de vida é montada recuada a certa distância (usualmente em torno de $1,5 \mathrm{~m}$ ) da periferia, presumivelmente para reduzir a distância de queda livre. A distância varia em função do contorno da periferia da superfície a ser protegida e da estrutura da laje, em que a presença de vigas pode impedir a colocação de apoios da linha de vida em certas posições. No caso de telhados, também é comum instalar a linha de vida junto à cumeeira.

Geralmente, a linha de vida é montada a certa altura acima da superfície de trabalho, usualmente entre 1 e 2 metros, embora em alguns casos seja colocada rente ao piso, e, em outros, mais próxima do teto.

Laborare. Ano I, Número 1, Julho/2018, pp. 151-179. ISSN 0000-0000. http://trabalhodigno.org/laborare 
Análise de riscos do uso de um sistema de proteção contra quedas com linha de vida horizontal como proteção de periferia na Construção Civil brasileira

Geralmente, o SPAQ se destina a proteger contra uma queda a partir da borda dessa superfície. Em alguns casos, porém, também se destina a proteger contra uma queda através da superfície frágil, devido á ruptura dessa superfície, como em telhados, clarabóias, formas, bandejas e andaimes.

Quanto às tarefas a serem protegidas, por vezes, o SPAQ se destina a proteção durante a execução de múltiplas tarefas, executadas simultânea ou sucessivamente no tempo, em um ou mais níveis. Por exemplo, durante a execução da estrutura de um edifício, uma linha de vida pode se destinar a proteger, em uma primeira etapa, a tarefa de execução da forma dos pilares, em que o trabalhador se posiciona sobre a laje já concretada. A seguir, a execução da forma das vigas e lajes, mas com o trabalhador posicionado sobre um andaime móvel de pequena altura sobre a laje concretada. Depois, o trabalhador está sobre a forma, para colocar as armações metálicas e tubulações elétricas, e então lançar o concreto. Mais tarde, o trabalhador está no pavimento abaixo do que foi concretado, fazendo a desforma. E mais tarde ainda, construindo a parede de alvenaria. Às vezes, mais de um nível de linha de vida é montado em um mesmo suporte vertical, permitindo a realização de mais de uma dessas etapas simultaneamente. O SPAQ também pode se destinar a proteger durante a montagem de um SPPQ, como um guarda-corpo, no caso desses dois tipos de proteção serem utilizados em momentos diferentes.

É importante considerar a configuração do SPAQ: os modelos de EPI utilizados, comprimentos e características dos componentes de união, qual a altura da linha de vida horizontal sobre o pavimento, e qual o afastamento da periferia, o número de vãos, os comprimentos e as flechas dos vãos, a existência de absorvedor de energia na linha, esticador e indicador de tensão. Algumas linhas de vida utilizam pontos de ancoragem móvel que podem transpor as ancoragens intermediárias sem desconectar

Laborare. Ano I, Número 1, Julho/2018, pp. 151-179. ISSN 0000-0000. http://trabalhodigno.org/laborare 
o talabarte, ou em que dois trabalhadores podem trocar de posição sem ter que desconectar os talabartes. Esses dispositivos aumentam muito a segurança do sistema.

\section{ANÁLISE DE RISCOS: IDENTIFICAÇÃO DOS RISCOS, CAUSAS E CONSEQUÊNCIAS}

Levando em consideração as características do sistema acima descritas, fez-se a identificação dos riscos, suas causas e consequências, através da técnica de análise de modos de falha e efeitos (ABNT, 2012).

1. O primeiro modo de falha, que é a mais comum e é fatal, é que o trabalhador não estar conectado ao sistema de ancoragem no momento da queda. Essa falha decorre diretamente do fato do sistema de proteção contra quedas utilizado ser do tipo de proteção ativa. Contribuem para a ocorrência dessa falha:

1.1. O SPAQ com linha de vida horizontal flexível é indicado quando a necessidade de movimentação é linear. No caso de uso para proteção de periferia, há necessidade de movimentação por toda a superfície, não apenas na periferia, onde a linha de vida está situada. O sistema presume que o trabalhador se conecte na linha de vida ao se aproximar da periferia da superfície e se desconecte ao se afastar da periferia. Isso leva a frequentes conexões e desconexões, que aumentam a chance de que o trabalhador acabe por não se reconectar.

1.2. Um risco estritamente ligado ao anterior é que a conexão não é exigida de todos os empregados no pavimento ou não é exigida todo o tempo. A linha de vida existe somente na periferia do pavimento. Isso faz com que os que estão trabalhando mais ao centro não possam se conectar. Às vezes, ao transitar do centro para a periferia, o trabalhador não faz a conexão. Um 
Análise de riscos do uso de um sistema de proteção contra quedas com linha de vida horizontal como proteção de periferia na Construção Civil brasileira

SPAQ deve permitir que o trabalhador fique conectado ao sistema durante todo o tempo de exposição ao risco de queda (NR 35, 35.5.11 a). Se a periferia não é protegida por um SPPQ, não há uma distância definida em que o risco de queda seja inexistente.

1.3. Em alguns pontos, não é possível realizar o trabalho estando conectado. $\mathrm{O}$ trabalhador não consegue alcançar o ponto em que precisa realizar o trabalho. É um problema de projeto do sistema.

1.4. A conexão dificulta o trabalho e diminui muito a produtividade. A chance de que o trabalhador acabe por deixar de se conectar é muito grande.

1.5. É necessário desconectar e reconectar frequentemente. Há uma tendência de que o trabalhador acabe não se reconectando, especialmente nos momentos em que o ritmo de trabalho é mais intenso. Como já mencionado, existem produtos disponíveis comercialmente que possibilitam passar por ancoragens intermediárias e por outros trabalhadores sem desconectar, mas é raro que esses produtos sejam utilizados na indústria da construção, talvez devido ao custo ou ao fato de não haver o costume de utilizá-los.

1.6. O número de trabalhadores no pavimento é maior do que o que pode se conectar na linha de vida horizontal flexível. As linhas de vida são projetadas para um número limitado de trabalhadores por vão. O mais comum são dois trabalhadores por vão. Muitas vezes, o número de trabalhadores é superior, na região de um determinado vão, o que leva a que nem todos se conectem. $\mathrm{Ou}$, que eles se conectem em número acima da capacidade da linha de vida, o que pode ocasionar a ruptura da mesma.

Laborare. Ano I, Número 1, Julho/2018, pp. 151-179. ISSN 0000-0000. http://trabalhodigno.org/laborare 
1.7. Há espaços abertos no interior da superfície que ficam sem proteção contra quedas. Por exemplo, quando o assoalhamento de formas de lajes é feito por cima, há vãos em que o assoalho da forma ainda não foi colocado, por onde o trabalhador pode cair (ver figura 2). Esses vãos estão no meio do pavimento, mas a linha de vida geralmente só é colocada próximo à periferia. É um problema de concepção do sistema.

Figura 2 Montagem de formas. A linha de vida horizontal não oferece proteção contra quedas da borda da área que está sendo assoalhada

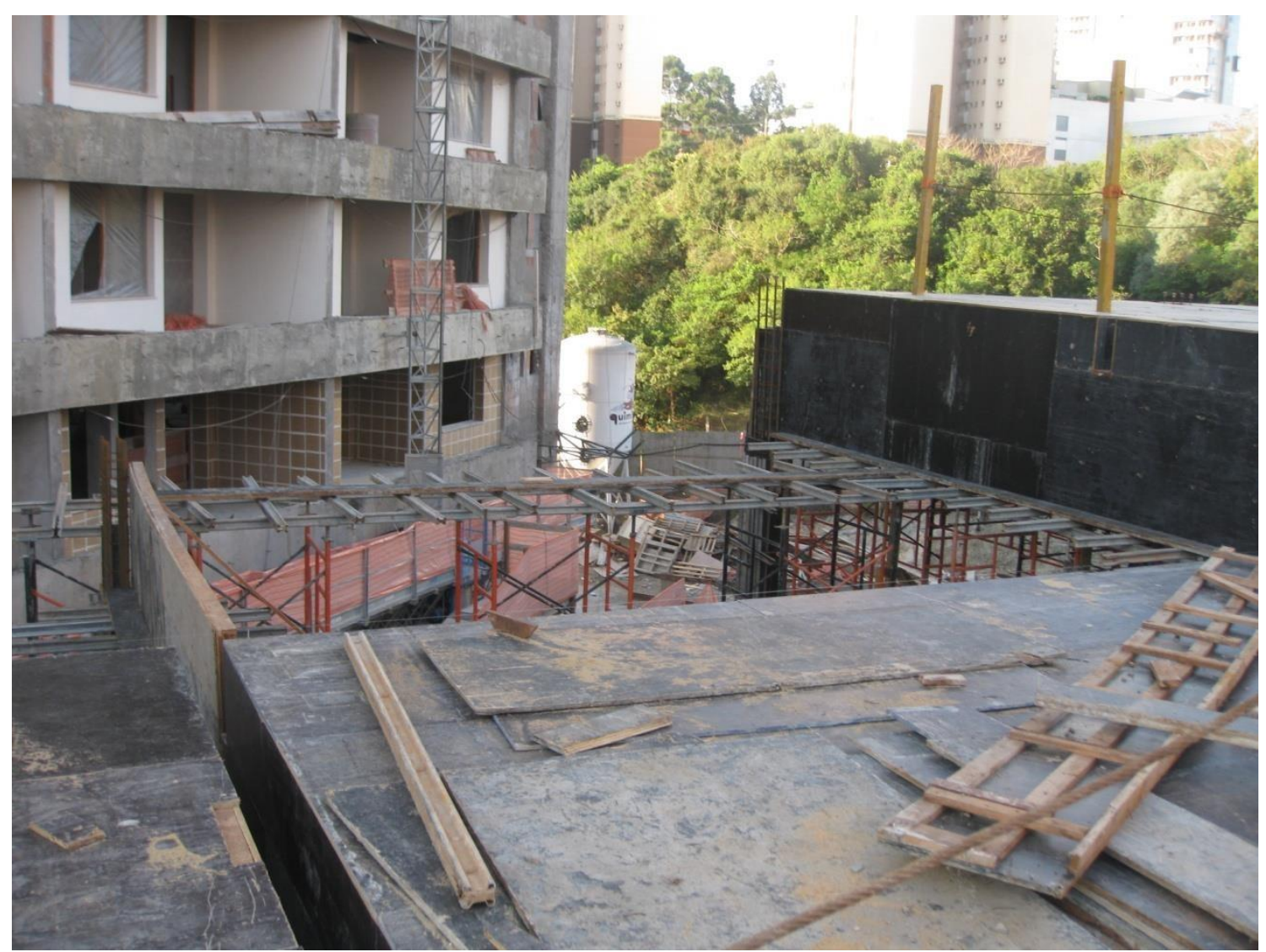

Foto do Autor

1.8. Ausência de supervisão.

Laborare. Ano I, Número 1, Julho/2018, pp. 151-179. ISSN 0000-0000. http://trabalhodigno.org/laborare 
Análise de riscos do uso de um sistema de proteção contra quedas com linha de vida horizontal como proteção de periferia na Construção Civil brasileira

1.9. Tolerância da empresa com a falta de conexão do EPI ao sistema de ancoragem. Ao constatar a falta de conexão, a empresa se limita a advertir o trabalhador, sem investigar os motivos porque isso ocorreu, e continua autorizando o trabalho em altura, ao invés de revogar essa autorização.

2. Sistema de restrição de movimentação em que há possibilidade de ocorrer uma queda. Esse tipo de sistema não está preparado para ocorrência de queda. Não há absorvedor de energia; o sistema de ancoragem não está dimensionado para resistir às forças maiores da retenção de queda, nem há verificação da zona livre de queda. Nessas condições, se ocorre uma queda, pode ser fatal. Por isso, deve-se estar absolutamente seguro de que uma queda não ocorrerá. Deve haver uma distância de segurança da periferia do pavimento. Também o pavimento não pode ser frágil. Porém, em muitos casos, essas condições não são atendidas, mas o sistema é inadequadamente projetado como de restrição de movimentação. Contribuem para isso:

2.1. Projeto inadequado do SPAQ; para alcançar alguns pontos, o comprimento do talabarte necessita ser grande, mas em outros pontos em que a linha de vida está mais próxima da periferia, o comprimento é excessivo, permitindo a queda (ver figura 3).

2.2. Uso de extensores de talabarte.

2.3. Ajuste inadequado; o sistema é montado diferente do imaginado no projeto, ou o EPI não é ajustado bem, gerando folgas maiores que as previstas. Se não foi mantida a distância de segurança da periferia, pode haver uma queda. 
Figura 3. Importância do comprimento correto do talabarte de segurança em um sistema de restrição

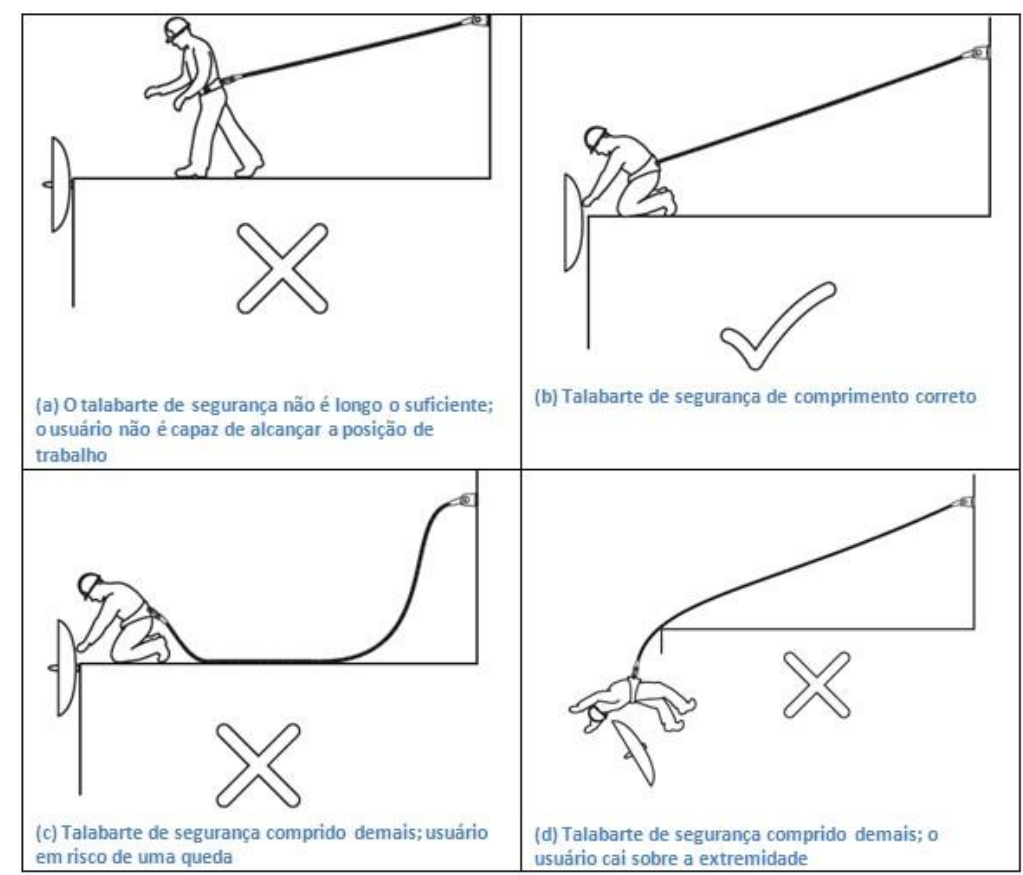

BRASIL, 2018; ABNT, 2017

3. Em sistemas de retenção de quedas, podem ocorrer as seguintes falhas:

3.1. O SPAQ não retém a queda:

3.1.1.Isso pode ocorrer se o sistema não foi adequadamente projetado, ou o projeto não foi adequadamente executado. A questão do projeto do SPAQ com linha de vida horizontal flexível em geral já foi abordada em outras obras (SOUZA; BRANCHTEIN, 2009; BRANCHTEIN, 2013, 2017; BRANCHTEIN, SOUZA; SIMON, 2015). No presente artigo, a análise é limitada aos fatores diretamente relacionados com o 
Análise de riscos do uso de um sistema de proteção contra quedas com linha de vida horizontal como proteção de periferia na Construção Civil brasileira

uso do SPAQ com linha de vida horizontal flexível para proteção de periferia de um pavimento.

3.1.2. Contato com arestas aguçadas. No uso do SPAQ com linha de vida horizontal flexível para proteção de periferia de um pavimento, quando ocorre uma queda, o componente de união do EPI entra em contato com a aresta do pavimento (ver figura 4). Nessa situação, o talabarte, ou o cabo do trava quedas retrátil, passa sobre uma aresta com pequeno raio de curvatura, uma força cortante concentrada é aplicada transversalmente ao talabarte simultaneamente à força de tração. Com isso, pode ocorrer ruptura em valores inferiores aos que ocorrem nos ensaios dos EPI, em que há apenas a força de tração. Em estudo feito pelo BGIA (2006b), foram testados vários tipos de EPI (talabarte, TQ retrátil, TQ deslizante), em vários tipos de borda aguçada (aço, telha metálica, concreto, madeira). Ocorreram um grande número de falhas $(55 \%)$ por rompimento da linha ou forças de pico acima de $6 \mathrm{kN}$. O estudo conclui que, como regra geral, o uso horizontal de EPI contra quedas deve ser evitado. Se isso não for possível, utilizar somente EPI ensaiado para uso em bordas aguçadas. O manual de instruções do EPI deve dar instruções precisas sobre o uso horizontal seguro, especialmente sobre os tipos de bordas aceitáveis. A norma americana ANSI Z359.14 (ANSI, 2012) tem ensaios para o uso horizontal de trava-quedas retráteis. No âmbito da norma europeia, existe uma recomendação de uso, VG11 CNB/P/11.060 (CNB, 2012), com conteúdo semelhante. 
Figura 4. Talabarte em uso horizontal entra em contato com borda aguçada

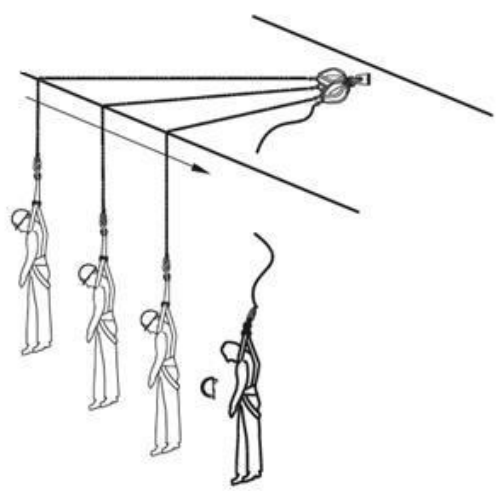

BRASIL, 2018; ABNT, 2017

3.1.3. Componentes do SPAQ incompatíveis entre si. Em alguns casos, usa-se um trava-quedas retrátil acoplado à linha de vida horizontal. Alguns trava-quedas retráteis apresentam problemas de compatibilidade com sistemas de ancoragens elásticos, como uma linha de vida horizontal flexível. Ao ocorrer uma queda, o travaquedas bloqueia, fazendo a retenção da queda, ocorrendo uma breve parada, e após a elasticidade da ancoragem puxa o corpo do trabalhador para cima, o que faz com que o trava-quedas volte a destravar, ocorrendo nova queda. O ciclo de travar e soltar pode continuar, e há risco de o trabalhador se chocar contra alguma estrutura. A ocorrência dessa condição depende das características do trava-quedas retrátil, da ancoragem e da massa do trabalhador (quanto mais leve mais provável). Para prevenir isso, devese usar um trava-quedas retrátil que informe ser compatível com ancoragens elásticas, ou utilizar uma ancoragem rígida, como uma linha horizontal rígida. (Sulowski, 2018). 
Análise de riscos do uso de um sistema de proteção contra quedas com linha de vida horizontal como proteção de periferia na Construção Civil brasileira

3.1.4. EPI utilizado além dos limites. Por exemplo, quando o componente de união é usado fora da vertical. Pelas normas brasileiras de EPI, os componentes de união, seja talabarte fixo, ou trava-quedas retrátil ou deslizante, são ensaiados apenas em uma queda vertical. Os travaquedas retráteis costumam ter instruções limitando o uso até 30 ou 40 graus com a vertical (ver figura 5). Havendo deslocamento inclinado, como no caso de telhados, ou horizontais, como no caso de lajes, deve-se verificar se o manual de instruções informa que o equipamento pode ser usado dessa forma. Caso contrário, deve-se consultar o fabricante. $\mathrm{O}$ uso fora dos limites pode ocasionar que o trava-quedas não bloqueie a queda, leve mais tempo para bloquear, atingindo uma distância de queda livre maior do que a de ensaio, ou que a força de impacto seja maior do que a força máxima admissível, de $6 \mathrm{kN}$, ou até mesmo ultrapassar a resistência do EPI ou da ancoragem, ocasionando a ruptura e queda.

Figura 5. Manual de instruções de trava queda retrátil

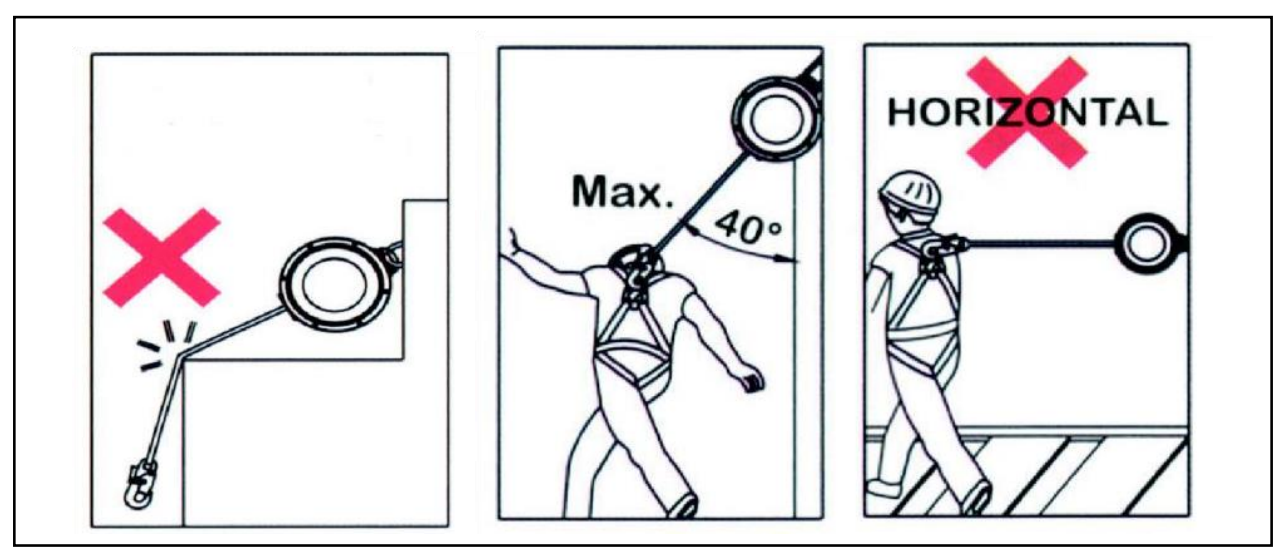

CARBOGRAFITE, 2016

Laborare. Ano I, Número 1, Julho/2018, pp. 151-179. ISSN 0000-0000. http://trabalhodigno.org/laborare 
3.1.5.No uso de trava-quedas retrátil ou deslizantes na horizontal ou inclinado sobre um telhado, bandeja ou andaime frágeis, se ocorre a ruptura da superfície, pode haver uma distância de queda livre muito maior do que a existente nos ensaios dos EPI (ver figura 6). Também pode haver quedas em pêndulo.

\section{Figura 6. Ruptura de superfície frágil}

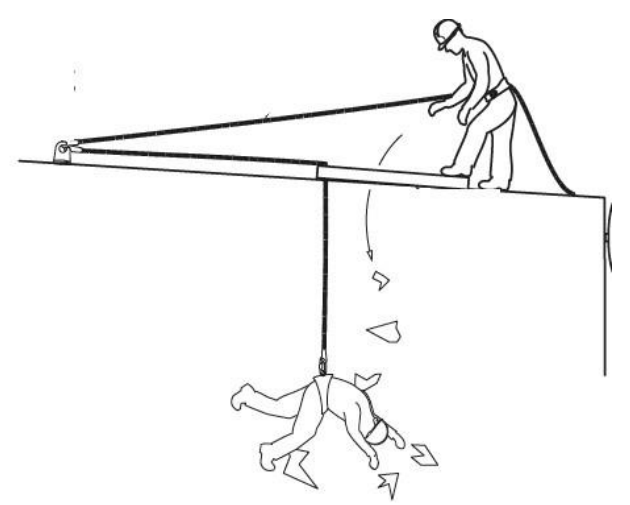

BRASIL, 2018; ABNT, 2017

3.2. Ocorre colisão com estruturas antes de finalizar a retenção da queda

3.2.1. Colisão com plano horizontal inferior, por não haver Zona Livre de Queda (ZLQ) suficiente. Pode ocorrer quando há queda da forma para a laje concretada logo abaixo. Mesmo que o talabarte esteja conectado à linha de vida, geralmente a ZLQ é insuficiente.

3.2.2. Colisão com estruturas ao lado do percurso de queda. No uso de SPAQ com linha de vida horizontal flexível para proteção de periferia de um pavimento, em alguns casos pode haver queda em pêndulo, fazendo com que haja colisão com um pilar ou com a quina da laje logo abaixo (ver figura 7). 
Análise de riscos do uso de um sistema de proteção contra quedas com linha de vida horizontal como proteção de periferia na Construção Civil brasileira

\section{Figura 7. Queda em pêndulo}

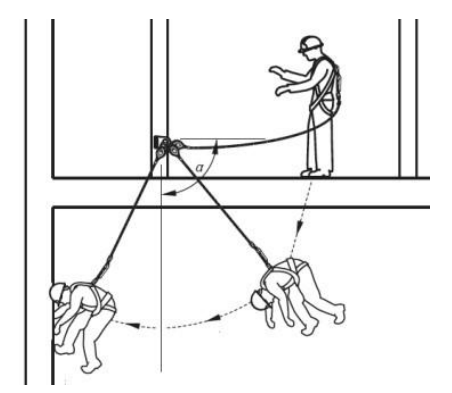

BRASIL, 2018; ABNT, 2017

3.2.3.Impacto contra estruturas perfurocortantes. Em alguns casos, há estruturas pontiagudas que se projetam da construção, como os parafusos tensionadores das formas (ver figura 8). O contato com as mesmas durante a queda pode causar ferimentos graves.

Figura 8. Objetos perfurocortantes na trajetória de queda

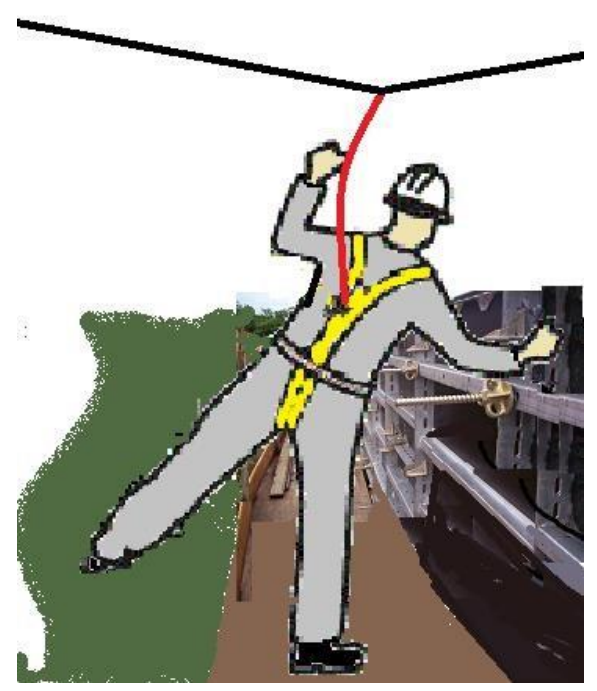

BRASIL, 2018

Laborare. Ano I, Número 1, Julho/2018, pp. 151-179. ISSN 0000-0000. http://trabalhodigno.org/laborare 
3.3. As forças de retenção de queda excedem o admissível:

3.3.1.Esgotamento do absorvedor de energia antes do término da retenção da queda, quando há um fator de queda maior do que dois em talabarte fixo ou uma distância de queda livre maior do que a ensaiada em trava-quedas retráteis ou deslizantes. Isso pode ocorrer se houver uso de extensores de talabarte ou quando a flecha da linha de vida se soma a distância de queda livre.

3.3.2. Uso do EPI além dos limites. Como já comentado acima, o uso de EPI além dos limites pode ocasionar que as forças de retenção de queda excedam o admissível. Por exemplo, se a massa total do trabalhador com equipamentos superar $100 \mathrm{~kg}$, poderá haver a exaustão do absorvedor de energia antes do término da retenção de quedas.

\section{CONCLUSÃO E RECOMENDAÇÕES}

$\mathrm{Na}$ análise de riscos efetuada no presente trabalho, verificou-se que no uso de um SPAQ ancorado em linha de vida horizontal flexível para proteção de periferia, há vários riscos de consequências potencialmente graves ou fatais. Tais falhas são amplamente prevalentes entre os sistemas de proteção contra quedas estudados. Além disso, alguns desses riscos, como o contato do talabarte com bordas aguçadas, são consequência direta da utilização do SPAQ ancorado em linha horizontal flexível como proteção de periferia, sendo riscos quase que inerentes a esse tipo de utilização do SPAQ.

Na maioria dos casos observados, verificou-se que não é sequer realizada análise de risco, sendo feito apenas o projeto. E mesmo quando realizadas, as análises de riscos não reconhecem as falhas listadas no presente trabalho, constituindo-se essas falhas em pontos cegos do sistema de proteção.

Laborare. Ano I, Número 1, Julho/2018, pp. 151-179. ISSN 0000-0000. http://trabalhodigno.org/laborare 
Análise de riscos do uso de um sistema de proteção contra quedas com linha de vida horizontal como proteção de periferia na Construção Civil brasileira

Também se verifica que há alternativas para proteção contra quedas do tipo passiva, como sistemas de guarda-corpos ou envelopamento da obra com andaimes fachadeiros. Assim, o uso de uma proteção ativa, com risco de falhas graves ou fatais não é justificável nem perante a hierarquia das medidas de controle requerida na norma regulamentadora NR 35 nem perante a obrigatoriedade de proteção coletiva contra quedas prevista na norma regulamentadora NR 18.

Recomenda-se, portanto não utilizar proteção ativa contra quedas como forma de proteção de periferia. Ao invés disso considerar a utilização de medidas de controle mais acima na hierarquia, como eliminação do trabalho em altura ou uso de sistemas de proteção passiva.

Se houver necessidade absoluta de utilizar o sistema de proteção ativa, proceder a uma análise de risco detalhada, considerando as condições específicas da tarefa, que aborde todos os riscos identificados no presente trabalho, buscando soluções adequadas para neutralizá-los. 


\section{REFERÊNCIAS BIBLIOGRÁFICAS}

ABNT (2012). NBR ISO/IEC 31010 Gestão de riscos — Técnicas para o processo de avaliação de riscos

ABNT (2014a). NBR 16325-1 Proteção contra queda de altura. Parte 1: Dispositivos de ancoragem tipos A, B e D.

ABNT (2014b). NBR 16325-2 Proteção contra queda de altura. Parte 2: Dispositivos de ancoragem tipos $\mathrm{C}$.

ABNT (2017). NBR 16489 Sistemas e equipamentos de proteção individual para trabalhos em altura - Recomendações e orientações para seleção, uso e manutenção.

ABNT (2018). NBR ISO 31000 Gestão de riscos - Diretrizes

ANSI (2012) Z359.14 Safety Requirements for Self-Retracting Devices for Personal Fall Arrest and Rescue Systems

BGIA (2006a) - BERUFSGENOSSENSCHAFTIICHES INSTITUT FÜR ARBEITSSCHUTZ. Fall arrest equipment when used in a horizontal arrangement. ISFP 2006.

BGIA (2006b) - BERUFSGENOSSENSCHAFTIICHES INSTITUT FÜR ARBEITSSCHUTZ. Report 2/2006e - Drop tests with PPE against falls from a height in a horizontal arrangement. 2006.

BRANCHTEIN M. C.; SOUZA G. L. (2009), Análise de Acidentes do Trabalho na Indústria da Construção no Rio Grande do Sul entre 2002 e 2009. In: VI CMATIC CONGRESSO NACIONAL SOBRE CONDIÇÕES E MEIO AMBIENTE DO TRABALHO NA INDÚSTRIA DA CONSTRUÇÃO, Belém do Pará, 6 a 9-12-2009. Disponível em: http://wikitrabalho.agitra.org.br/sst/arquivos. Acesso em: 28-06-2018.

BRANCHTEIN M. C. (2013), Lifeline design: calculations of the tensions (Projeto de Linha de Vida: Cálculo das tensões). In: 2013 ISFP SYMPOSIUM (Simpósio da Sociedade Internacional de Proteção contra Quedas), Las Vegas, NV, USA, em 2806-2013. Disponível em: http://wikitrabalho.agitra.org.br/sst/arquivos. Acesso em: 28-06-2018.

BRANCHTEIN M. C.; SOUZA G. L.; SIMON, W. R. (2015). Sistema de proteção ativa contra quedas com linha de vida horizontal flexível. In: FILGUEIRAS, V. A. (Org.) et al. Saúde e segurança do trabalho na construção civil brasileira. Aracaju: J. Andrade, 2015. Disponível em: http://wikitrabalho.agitra.org.br/sst/livros. Acesso em: 28-06-2018.

Laborare. Ano I, Número 1, Julho/2018, pp. 151-179. ISSN 0000-0000. http://trabalhodigno.org/laborare 
Análise de riscos do uso de um sistema de proteção contra quedas com linha de vida horizontal como proteção de periferia na Construção Civil brasileira

BRANCHTEIN M. C. (2016), Brazilian Laws and regulations on Work at Height. In: 2016 ISFP SYMPOSIUM (Simpósio da Sociedade Internacional de Proteção contra Quedas), Atlanta, GA, USA, em 29-06-2016. Disponível em: http://wikitrabalho.agitra.org.br/sst/isfp2016. Acesso em: 28-06-2018.

BRANCHTEIN M. C. (2017); Riscos de queda - sistema de proteção individual. In: FILGUEIRAS, V. A. (Org.) et al. Saúde e Segurança do Trabalho - Curso Prático. Brasília: ESMPU, 2017. Disponível em: http://wikitrabalho.agitra.org.br/sst/livros/sstcurso-pratico-espmu. Acesso em: 28-06-2018.

BRASIL. (1943). Decreto-Lei N. ${ }^{\circ} 5.452$, de $1^{\circ}$ de maio de 1943. Consolidação das Leis do Trabalho.

BRASIL. (1988). Constituição da República Federativa do Brasil.

BRASIL (2008). Ministério do Trabalho e Emprego. Superintendência Regional do Trabalho e Emprego no Rio Grande do Sul. Análises de acidentes do trabalho fatais no Rio Grande do Sul: a experiência da Seção de Segurança e Saúde do Trabalhador SEGUR. MTE/SRTE-RS/SEGUR, Porto Alegre, 2008. Disponível em: http://wikitrabalho.agitra.org.br/sst/livros/analise-de-acidentes. Acesso em: 28-06-2018.

BRASIL. (2015a). Ministério do Trabalho e Emprego. NR 6 - Equipamento de Proteção Individual - EPI. Redação da Portaria SIT 25, de 15-10-2001, e alterações posteriores, até Portaria MTE 505, de 16-04-2015.

BRASIL. (2015b). Ministério do Trabalho e Emprego. NR 18 - Condições e Meio Ambiente do Trabalho na Indústria da Construção. Redação dada pela Portaria SSST 04, de 04-07-1995 e alterações posteriores, até a Portaria MTPS 208, de 08-12-2015.

BRASIL. (2016). Ministério do Trabalho e Emprego. NR 35 - Trabalho em Altura. Redação da Portaria SIT 313, de 23-03- 2012, e alterações posteriores, até a Portaria MTE 1113, de 21-09-2016.

BRASIL. (2018). Ministério do Trabalho e Emprego. Secretaria de Inspeção do Trabalho. Manual de Auxílio na Interpretação e Aplicação da Norma Regulamentadora 35 - Trabalho em Altura - incluindo anexos I e II e alteração do item 35.5 - NR-35 Comentada. Brasília. 04-04-2018.

BSI (2007). BS OHSAS 18001:2007. Occupational health and safety management systems. Requirements.

CARBOGRAFITE (2016). Manual de instruções. Trava queda retrátil CG 500 N. Trava queda retrátil Evolution. Jun/2016.

CNB - EUROPEAN COORDINATION OF NOTIFIED BODIES FOR PERSONAL PROTECTIVE EQUIPMENT (2012). CNB/P/11060 rev. 7 Recommendation for

Laborare. Ano I, Número 1, Julho/2018, pp. 151-179. ISSN 0000-0000. http://trabalhodigno.org/laborare 
Use: What tests are necessary for retractable type fall arresters intended for horizontal use over an edge?

HOLLNAGEL, E. (2004). Barriers and Accident Prevention. Ashgate, Hampshire, 2004.

ILO. INTERNATIONAL LABOR ORGANIZATION (2001). Guidelines on occupational safety and health management systems, ILO-OSH 2001. Genebra, ILO, 2001.

ILO (1988). Convention 167 Safety and Health in Construction.

ILO (2018). Safety and health at work. http://www.ilo.org/global/topics/safety-andhealth-at-work. Acessado em 31-03-2018.

ISO (2018). ISO 45001:2018 Occupational health and safety management systems. Requirements with guidance for use.

SOUZA G. L.; BRANCHTEIN M. C. (2009), Dimensionamento de sistema de cabo de aço sujeito a uma ação transversal. In: VI CMATIC - CONGRESSO NACIONAL SOBRE CONDIÇÕES E MEIO AMBIENTE DO TRABALHO NA INDÚSTRIA DA CONSTRUÇÃO, Belém do Pará, 6 a 9-12-2009. Disponível em: http://wikitrabalho.agitra.org.br/sst/arquivos. Acesso em: 28-06-2018.

SULOWSKI, A. (2018). Hazard Alert HA-009. Self-Retracting Lifeline Hazard Alert No. 2. Disponível em http://www.fallpro.com/fall-protection-info-center/hazardalerts/self-retracting-lifeline-alert-2/. Acesso em: 31 mar. 2018. 